\title{
PAPER CUTS: The Early Modern Fugitive Print
}

\author{
Rosemary Moore
}

工

ayer by layer the body is peeled away. First the skin of the torso is stripped back revealing the heart, liver kidneys. These are pushed aside, bringing into visibility the reproductive organs and a tiny curled foetus with hands covering the ears in a protective gesture. But this anatomy is not performed by an official anatomist, or even by the barber surgeon who would have been responsible for opening up the body during the highly ordered and ritualistic public anatomical lesson. Rather it is the user of the print who performs the anatomy, enabled by an innovative assemblage of printed cut-outs and paper flaps. This print is what is known as an anatomical fugitive sheet, first produced around I 538 in Germany by the printer/engraver Heinrich Vogtherr the Elder (figures I and 2). A year later Hans Guldenmundt produced a pair of fugitive sheets, depicting male and female figures in the guise of Adam and Eve. All of these prints were copied widely; at least fifteen different editions were made between the years I $538-$ I 540 . $^{\text {I }}$ This success was perhaps encouraged by a novel variation on the standard anatomical print, changing the two dimensional image to an animated one. But because they were printed as loose leaf broadsheets rather than pasted or bound into books many were lost, discarded, or damaged. The history of why and how the prints were made is equally difficult to trace and their uses are a matter of speculation, especially as relatively few fugitive sheets remain intact.

If fugitive sheets produce knowledge, it is through the act of cutting, marking and inscribing on the body. These cuts are both literal and imagined by the users of fugitive sheets, and can be conceived of in two ways. Firstly the sheets are, at least partly, concerned with medical knowledge - the production of which involves the anatomist cutting into, fragmenting then dividing the body in order to reveal its internal secrets. The scalpel pierces the skin's boundary in order to open up the body and the knowledge to be 


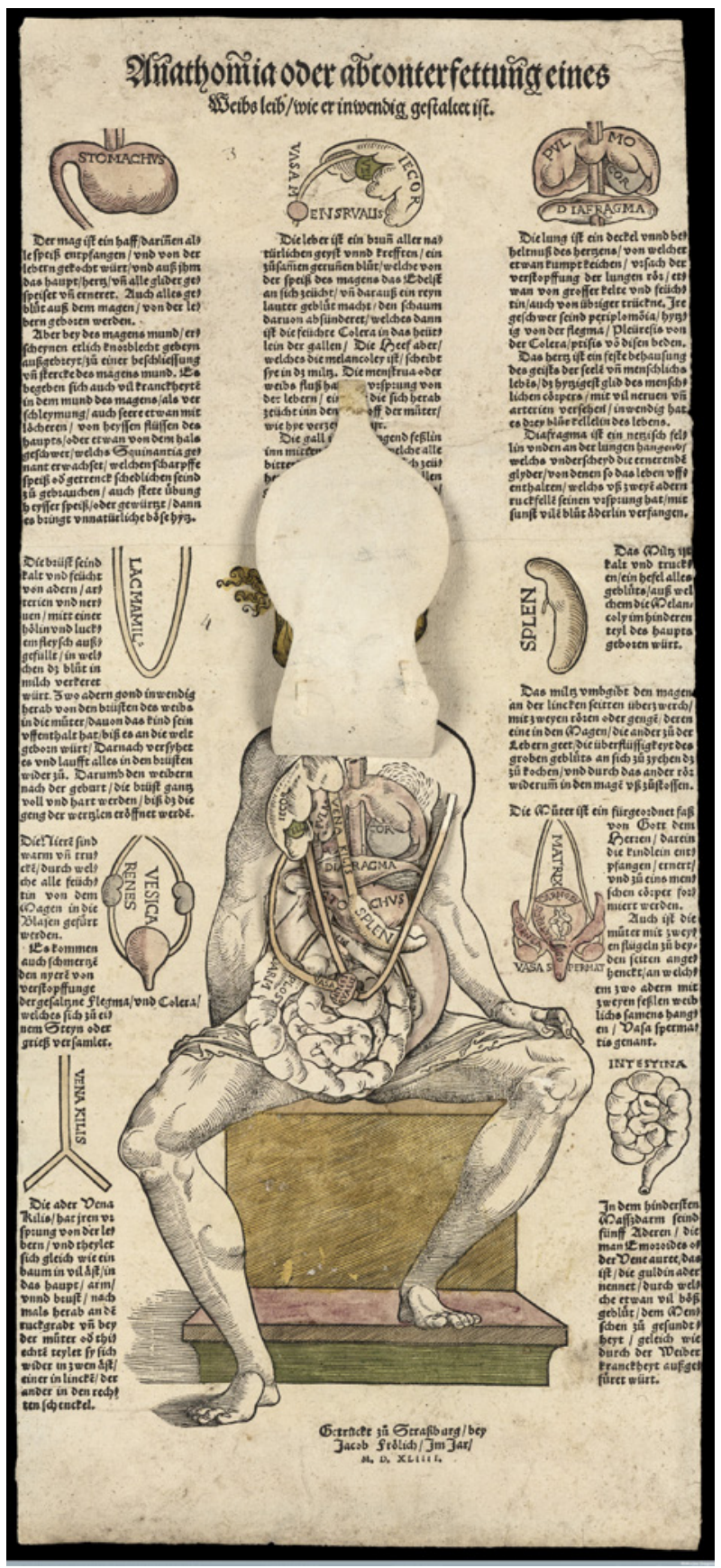

Figure I Jacob Frölich (after Heinrich Vogtherr), Anatomy, or, a faithful reproduction of the body of a female (Anathomia oder abconterfettung eines Weibs leib), i 564 . Woodcut, $52 \times 23.9 \mathrm{~cm}$. The Wellcome Library, London, Photo: Wellcome Library. 


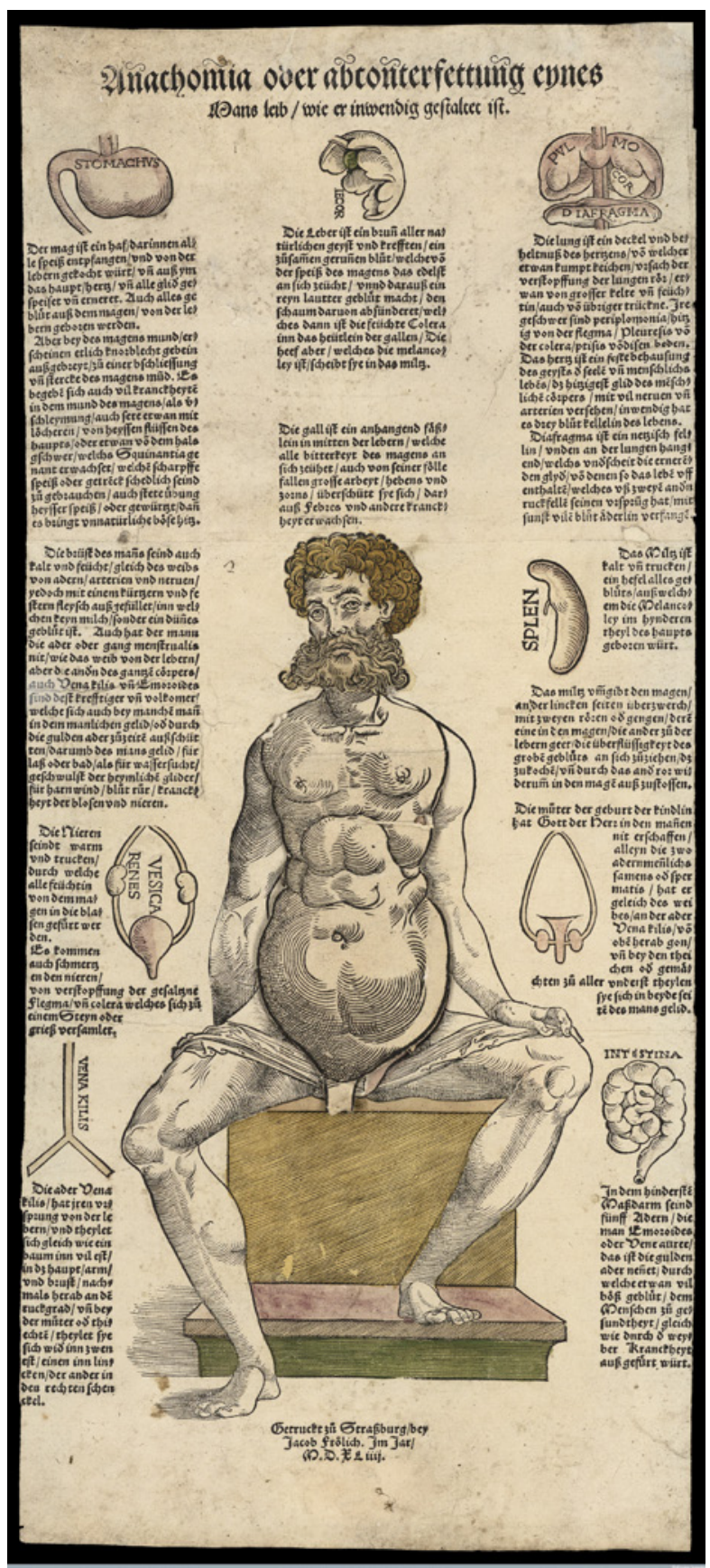

Figure 2 Jacob Frölich (after Heinrich Vogtherr), Anatomy, or, a faithful reproduction of the body of a male (Anathomia oder abconterfettung eines Mans leib), I 544. Woodcut, $52 \times$ $23.9 \mathrm{~cm}$. The Wellcome Library, London. Photo: Wellcome Library. 
acquired from looking inside it, to the viewer's inquisitive gaze. The cut, however, conjoins as well as divides the body - it brings together different kinds of knowledge, making them visible on the body's surfaces. Secondly, the notion of cutting into or incising is also activated through the technology of print itself. Visual information is formed and constructed by repeatedly cutting lines, marks and forms into the woodblock. Metaphors of cutting into the body and inscribing knowledge through technologies of printing thereby converge in the sheets and this is further heightened by the viewer's physical interaction with the cut; in effect the user of the print repeats the cut as they lift the moveable paper flaps. What is brought into visibility and what remains outside of visibility are entirely dependent on multiple concepts and negotiations of the cut.

Notions of cutting into or inscribing have long been conceived as a way to form knowledge in print, but have all too readily been associated with permanence, and the success of representation in securing knowledge. I will open up the idea of the cut as both producing and challenging representation. In anatomical illustration the cut seeks to order and contain the body by establishing a critical distance from the bloody realities of dissection. But this is only part of a prescribed goal. In fact, the cut does much more than simply re-order the body and separate it into comprehensible parts. The cut also demarcates the relation between body, space and time, by enabling viewers to experience the body not as a flat image but as a spatialized, animated object. In the process it also produces a new relationship between image and viewer.

Fugitive sheets are not easily situated in art historical discourse and have often been dismissed as mere curiosities, aimed at uneducated audiences. Attempts to situate them in art history have focused on establishing a genealogy and they have been categorised as 'popular', a term with a long and complicated history in the study of print culture, which presumes an uneducated audience and an unsophisticated usage. ${ }^{2}$ The idea that 'popular' print frequently held a moralizing purpose is one of the legacies of the category, however I propose that fugitive prints are not only more complicated than has been suggested, but also present a challenge to the all too neat separation between 'popular' print and professional medical print. Roger Chartier writes that the potential of print cannot be delimited by the assumption of an already established audience. ${ }^{3}$ It was actually print that called up users rather than the other way 
around. In line with Chartier's argument, I will refer to those who engaged with fugitive sheets as the prints' 'users'. Unlike other prints that mobilise the cut to make the body's interior visible, fugitive sheets go further, making the cut tangible and inviting users to engage with and activate the image, rather than passively receiving its prescribed message.

This is a very different approach to anatomical print than is usually presumed to operate within medical treatises. For instance, the woodcuts in Andreas Vesalius' 'On the fabric of the human body' of I 543, which not only belong to the canon of scientific knowledge, they have become foundational. Although in terms of knowledge they were very quickly superseded, as images they have gained in credibility, especially as the interests of the history of science and the history of art have started to intersect. Vesalius' prints have served to create the category of 'popular' print as much as the idea of 'popular' print has served to produce the prestigious category of professional medical knowledge. In fact this dichotomy is not helpful for thinking about either type of prints. It is the case that fugitive prints, unlike Vesalius' expensive treatise, were more accessible to different kinds of users, but it is the prints themselves that must suggest the possibilities and limits of their usage rather than a preconceived idea of the category of the 'popular'. The animated aspect of fugitive prints - their interactivity - has always made them too unruly to suit later conceptualizations of art or science, yet animation was a central concern in attempts to convey anatomical knowledge from the study of inert corpses. Vesalius himself pursued the potential of fugitive sheets for representing movement, animation and even change in relation to the body in the Epitome, also published in I 543 .

Arguments about the body's changing visibility and its transformation into knowledge are by now well known to historians of art and medicine. Michel Foucault's Discipline and Punish has perhaps made the most influential contribution to this field and still has much to offer to discussions of the relation between body and image. According to Foucault, the body's location in early modern European imagination was in the process of change. Taking the criminal body as an example, he emphasized the move away from the spectacle of the scaffold towards invisibility within the penitentiary and argued that along with this shift in visibility came a reconceptualization in which the body and life became separated. ${ }^{4}$ The practice of dissection is of course closely linked with forms of punishment; Vesalius' Fabrica alludes 
to this when it depicts an anatomised cadaver suspended by a noose from the gallows in order to display the jawbone. ${ }^{5}$ Although it is questionable whether dissection was perceived as an extension of punishment, Foucault's argument undermines this idea in so far as he argues that physical punishment increasingly became the most hidden part of the process of control. Yet he argues that along with the disappearance of the spectacle of the scaffold, the body took on new possibilities, reconceived as a site for the production of knowledge - the focus was no longer on marking the body with the crime, but on reforming the person through regulation and supervision. This was to be a new form of subjection that went hand in hand with the body as productive of knowledge. The anatomical body represents the culmination of this new drive to survey, examine and understand, and if the criminal body effectively disappeared from view then the anatomical body has to be seen as having replaced it as a site of subjection and productivity.

My argument on how the cut opens up a new way to think about these prints will be pursued through three strands. First I will examine how the image offers knowledge through new forms of visibility produced by the idea of cutting. The most important change is the spatialization of the body's interior, which is not the same as the representation of the interior of the body. I will argue for how the technology of print and the user's own participation forge an internal space which one can enter, traverse and order, and how in doing so the user also animates the image. But the cut also produces a new notion of the surface of the body and it is here, on the surface, that decorative or didactic accessory figures help to construct something as complex as gender, securing it as both a biological and social category. The second strand of my argument addresses the anatomical fugitive sheets produced in Wittenberg, a charged meeting point in the histories of printing and religious unrest during the Reformation. The prints produced in Wittenberg have been the subject of scholarly focus but unpacking how they have been located within art history will demonstrate how audiences were more diverse and meanings far more malleable than has previously been proposed. Finally I will examine the cut in relation to how users intervene in the highly ordered structure of the print. I start from the ephemeral character of fugitive sheets and focus on how their temporality brings forth multiple possibilities, including the possibility of failure and ultimately the undoing of bodily knowledge. 
In fugitive prints, it is the edges of the skin's boundary that offers an entry point into new forms of knowledge, but this boundary does not simply open a view into neutral bodily matter. The skin is also a threshold into an interior space long imagined and controlled through religious belief, medical learning, and changing politics. The challenge is to resist classification whilst considering the importance of fugitive sheets as they reveal the potentials and problems of the new technology of print, changing attitudes towards the body and the blurring of boundaries between one discipline and another. Yet as Michel de Certeau would argue, how can fugitive sheets be turned into knowledge, in this case art historical knowledge, without distorting their possibilities and containing their unruly ways?

\section{Bringing knowledge into (in)visibility through the cut}

The discovery of space has been defined as one of the 'key conceptual shifts' to take place in early-modern Europe, with anatomists' explorations of the body likened to "the study of the organization of space.'" This refers to an awareness of the physical space the body occupies in the world as well as the spatial relationship between interior and exterior. However, how to picture the body's spatialization had long posed a problem. Fugitive sheets achieved it through the combination of cuts gouged into the woodblock, which was inked and pressed to create an image of the body on paper. The resulting image was then itself cut into pieces and carefully layered over the area of the design illustrating the torso. Cutting was thus central to how the body was made visible and it was also through the cut that the image was animated.

Starting with the outermost view of Vogtherr's fugitive sheets, which were reissued by the Strasbourg publisher Jacob Frölich in I 544 (figures I and 2), the figures are seated on a stone plinth. Superimposed on top of this space are up to nine accessory figures illustrating the internal organs, accompanied by textual descriptions. The fixed pose and the repetition of the internal organs ensures that certain parts of the body, and therefore certain interpretations of it, are always visible no matter what stage of dissection the figure itself is in. But there are also a number of clues as to the animated potential of the image inscribed upon this first outer layer.

The figures' distinctive open legged pose resembles the position women adopted during childbirth. Before female birthing attendants were replaced 
by predominantly male medical professionals and control was displaced from the woman to the person delivering the child, it was far more common for women to give birth in a seated or squatting position rather than lying down on a bed. ${ }^{7}$ The open legged posture of the figures in these fugitive sheets thereby evokes a transition from one state to another, from interdependent part to autonomous whole. The pose itself may be fixed, as opposed to being layered with moveable parts such as the torso, but the change and the production of knowledge signals animation for the body.

The hands too hint at the animated potential of the image. They are carefully arranged to convey acquiescence and agency over the dissection the right hand is tucked away out of sight, but the left hand is poised on the thigh. Index finger and thumb delicately handle the fabric draped across the lap obscuring the genital region, almost as if they are poised to pull back the fabric and reveal the bodily secrets hidden beneath. And if the print's user looks closer still they notice creases in the paper around the neck making the edges of the torso curl up slightly; tantalizingly inviting users to peel back the outer layer of skin and reveal what lies hidden beneath the surface of the image.

Lifting each of the layers reveals the internal organs as they are brought into visibility through the cut (figure 3). Each part is examined and turned over until finally one arrives at the spinal column printed on the final sheet. Yet this does not represent the end of the process. The fugitive sheet promises 'infinite investigations' since by carefully replacing each layer the image is returned to its initial, complete state. The anatomized body is thus caught in a continual cycle of being torn apart, revealing knowledge, and then having this knowledge collapse back in on itself through the lifting, replacing and infinite rearranging of paper flaps.

Text plays an integral role in defining and controlling the production of meaning throughout this cycle. It aims to bring stability to the image and restrict what is brought into or concealed from view. The names of the various organs are printed onto each flap, but this information could potentially be overlooked, misplaced, destroyed or even used in conjunction with another image altogether. ${ }^{8}$ Additional strategies are required in order to secure meaning and, as I will show, even the internal organs are implicated in the attempts to define and defend socially constructed gender differences as distinctions between male and female threaten to be effaced by the cut. 


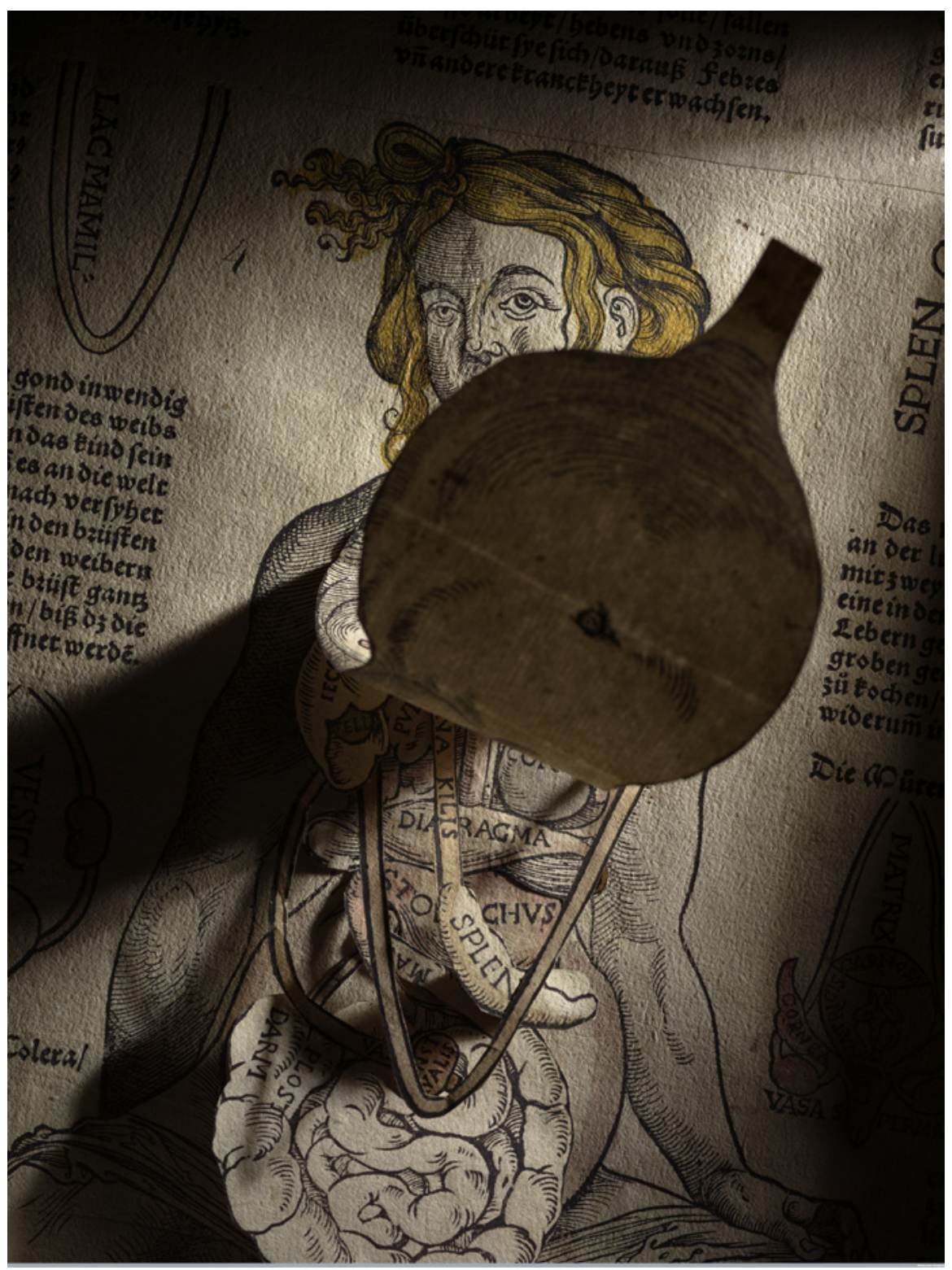

Figure 3 Jacob Frölich (after Heinrich Vogtherr), Detail of: Anatomy, or, a faithful reproduction of the body of a female (Anathomia oder abconterfettung eines Weibs leib), I 564 . Woodcut, $52 \times 23.9 \mathrm{~cm}$. The Wellcome Library, London, Photo: Wellcome Library. 
A conflict has emerged here between the attempt to spatialize and to clarify through a focus on the surface, not only of the body but also of the print. Comparing these fugitive sheets to the muscle-men from Vesalius' Fabrica reveals how surface ornamentation, the few constant elements of the composition that are not disrupted or obscured as users lift the flaps of the torso, also plays a strategic role in stabilizing the image and demarcating the limits of knowledge acquired from the body. It has often been remarked that despite being stripped of skin, the muscle men from the Fabrica nonetheless retain a sense of 'wholeness'. ${ }^{9}$ This, it is argued, is achieved through the active presentation of the idealized male figures, which are modelled on antique sculptures. ${ }^{10}$ The muscle men also mitigate any anxiety felt about cutting into the human body and elevate anatomical practices above their moral ambiguity by establishing a connection between Vesalius and his ancient predecessors. ${ }^{\text {II }}$ Whilst the visual strategies in Vesalius' prints are embedded within representation, for the fugitive sheet these are situated on the surface of the image. Since the internal organs reproduced around the peripheries of the page are always visible, like the texts that accompany them, they can tell us a great deal about what kind of knowledge the print aimed to instil. Indeed, this surface ornamentation is crucial to securing the boundaries between male/female in anatomical illustration.

There are striking similarities between the male and female figures in the fugitive prints. Torsos, arms, legs, feet and the plinths they are seated on are all clearly printed from the same woodblock, which was initially cut to illustrate the female figure. The male anatomy appeared a year later and the two were eventually issued together as part of a pamphlet Vogtherr authored, titled 'Interpretation and description of the human body'. ${ }^{\text {I2 }}$ In order to print the male figure the section of the block used for the head would have been left un-inked so that a second woodblock illustrating the man's head could be used in its place. His bushy beard no doubt proved to be an effective device for concealing the join where the two woodblocks meet at the neck, although in some prints it is still possible to discern the outline of the woman's head made by the impression of the un-inked block - visible as a faint halo around the head of the male figure. ${ }^{\mathrm{I} 3}$ This technique of printing both figures from the same block may have arisen out of the necessity to keep printing costs low. However, the reuse of the woodblocks was not without its problems. 
Similarities between the two figures belies socially constructed gender differences that are subjected to yet further deconstruction as the user cuts into and reveals visual information on the printed page. Thus the reuse of parts reveals how gender difference is: 'precariously attained and defensively secured.' ${ }^{14}$ Accessory organs therefore play a crucial role in defining the two genders and it is no coincidence that the reproductive organs and an unborn foetus are inscribed on the surface of representation. They ensure that woman's difference from man is always visible, always defining the female body. The significance of the foetus for defining the female body was clearly recognised by the anonymous printer of the fugitive sheets produced in Wittenberg in I573, which I will turn to next. For if gender is socially constructed then its deconstruction is implied along with the deconstruction of the human body under the anatomist's knife.

\section{Cutting to reveal the soul in each bodily part}

The cut thus produces a body both spatialized and flattened out, both animated and stilled. It also moves to socialize the body and produces order through gender differences. Moreover, the opening up of the body to learn its secrets ultimately meant gaining access to the soul, a notion that is frequently mobilized in anatomical literature, for instance in Vesalius' dissection of the heart, where he expresses surprise not to have found evidence of the soul. ${ }^{\text {Is }}$ Interestingly, some fugitive prints have become intricately connected to religious conflicts of the later sixteenth century. The triptych of fugitive sheets printed in Wittenberg in I 573 (figures 4, 5 and 6), has been discussed in relation to the active protestant politics of the region. Wittenberg and its university played an active role in the circulation of Protestant ideas, transforming practices of devotion and changing the way Protestant citizens conceived of the relationship between the spiritual and the material, part and whole.

Significantly, the printed text at the bottom of the third sheet from the triptych aligns the prints with Phillip Melanchthon's de Anima, the textbook used by students of Natural Philosophy at the University of Wittenberg, first published in I 540. ${ }^{16}$ Melanchthon (I497-I 560), was a Lutheran theologian and lecturer who played an important role in transforming the study of natural philosophy at the University of Wittenberg. ${ }^{17}$ For Melanchthon understanding human anatomy was integral to understanding the inseparable 


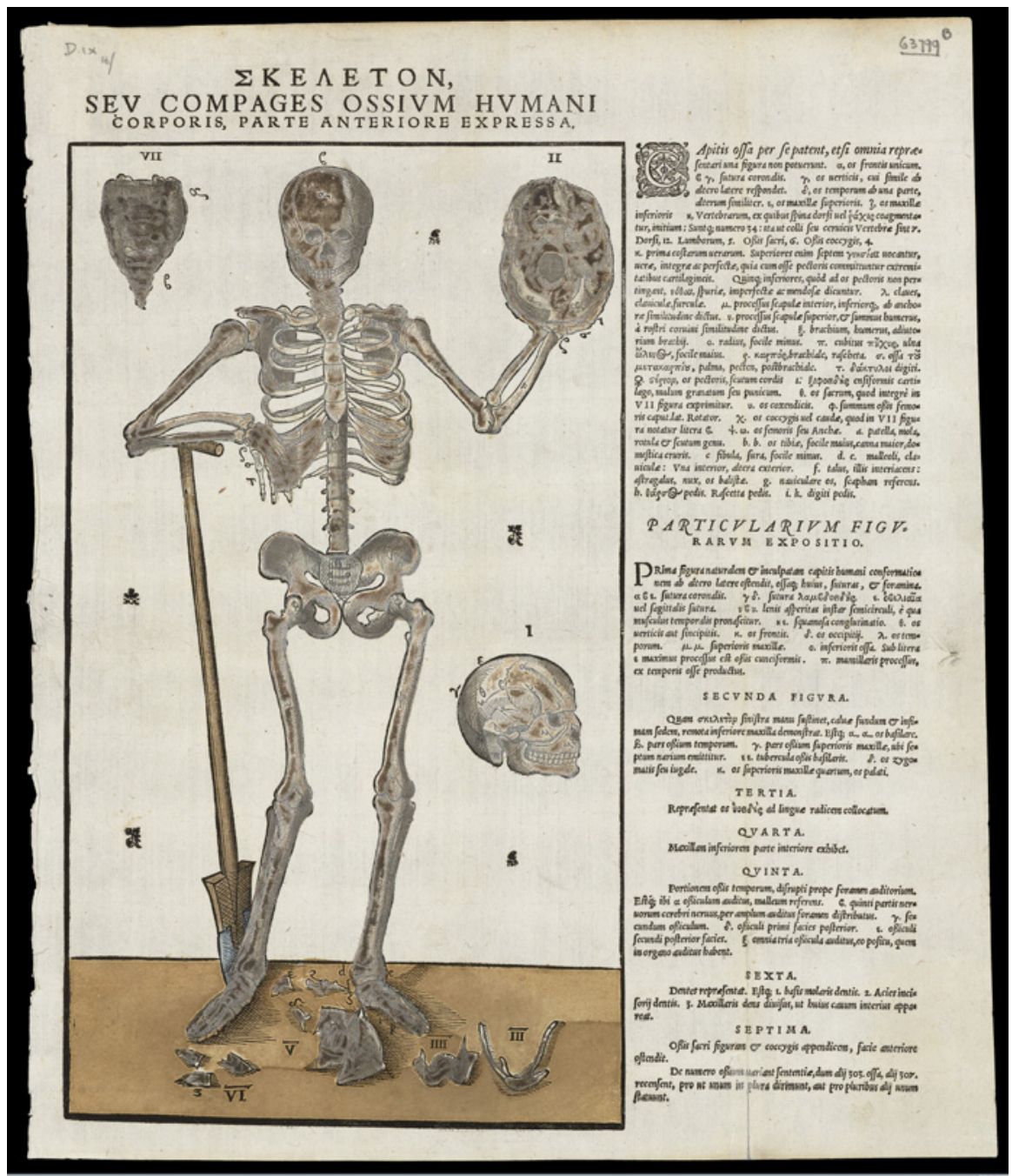

Figure 4 Anonymous printer, Skeleton from the Wittenberg triptych of fugitive sheets, I 573. Woodcut, $37 \times 3 \mathrm{I} \mathrm{cm}$. The Wellcome Library, London, Photo: Wellcome Library.

relationship between spirit (soul) and flesh and to accurately describe the Christian man; body and soul. ${ }^{\text {I } 8}$

An outcome of this connection with natural philosophy has been an emphasis on the moral call to self-knowledge, which has been central in the attempts by historians of art and medicine to describe and in effect 


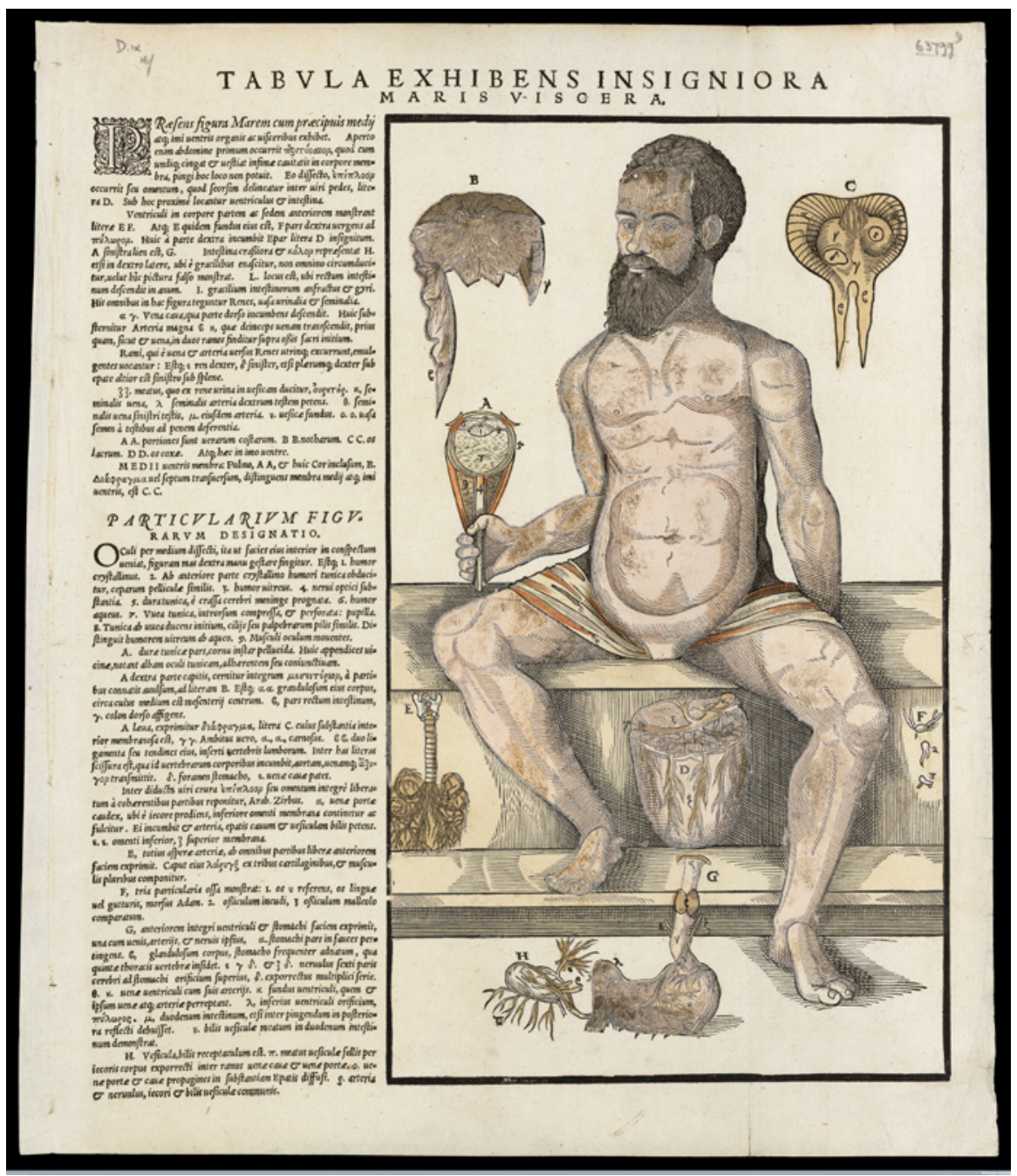

Figure 5 Anonymous printer, Male anatomical figure from the Wittenberg triptych of fugitive sheets, I 573. Woodcut, $37 \times 3 \mathrm{I} \mathrm{cm}$. The Wellcome Library, London, Photo: Wellcome Library. 


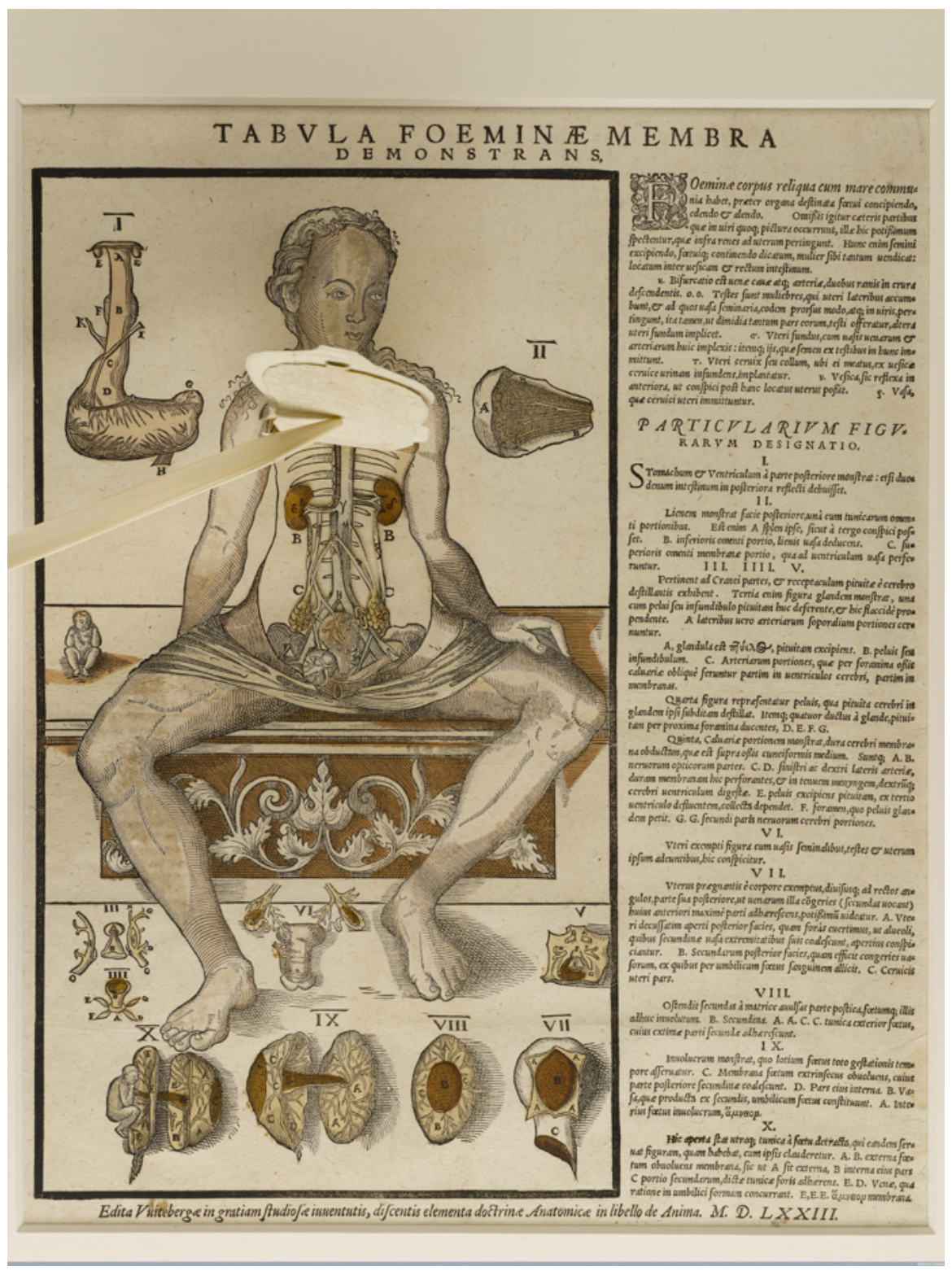

Figure 6 Anonymous printer, Female anatomical figure from the Wittenberg triptych of fugitive sheets, I 573. Woodcut, $37 \times 3 \mathrm{I} \mathrm{cm}$. The Wellcome Library, London, Photo: Wellcome Library. 
contain the prints. In this way they have been distinguished from the woodcuts for Vesalius' Fabrica, which have been constructed as more to do with the formation of knowledge rather than the imparting of morality. But this approach is in danger of over determining the limits of the prints and overlooking the ambiguities that the images still retain. The notion of know thyself, was already a much broader concept, appearing in all kinds of images about the body's relation to the world. Within cabinets of curiosities it was the motto that accompanied anthropomorphic images in which the body and the world were spatially intertwined but constantly becoming unhinged. In effect, these evoked self-awareness by encouraging the user of the cabinet to question the world rather than simply accepting prescribed notions of it. ${ }^{19}$ This call to self-awareness is implicitly tied to embodied experience, even if self-awareness is usually conceived in terms of a mind/body split. For Vesalius touch was part of self-awareness, something he stresses throughout the Fabrica, deploring those who: 'abstain from the use of the hands as from a plague. ${ }^{20}$ Moreover, in Vesalius' portrait for the Fabrica he is actively engaged in dissecting a corpse - his left hand firmly grips an anatomised arm, while the thumb and index finger of his right hand separate muscles from sinew. Such close physical proximity between the bodies of the corpse and the anatomist was not without its problems however and with his fingers 'entwined in entrails' it starts to become unclear exactly whose body is on display. ${ }^{21}$

The male figure from the Wittenberg triptych (figure 5) is identical to the portrait of Vesalius, with his distinctive beard and head slightly turned, almost as if he has just been distracted from the work that occupies him. ${ }^{22}$ The image of the anatomist and the anatomised body collapse in on one another in this print. What then does it mean for users of the fugitive sheet to anatomise the anatomist? One obvious implication is that it aligns new anatomical practices with the study of natural philosophy at Wittenberg. The skeleton from the first sheet of the triptych (figure 4), which leans against a spade as it contemplates a skull, seems to support this notion as it too is adapted from one of Vesalius' woodcuts. Littered about its feet are broken fragments of bone - indicating the violence it has wrought on the skull in order to attain knowledge from it. This closely associates the skeleton with anatomical endeavours rather than a moralizing function, implying that like its Vesalian counterparts, the skeleton in the Wittenberg sheets serves to re-orientate the relationship between the production of anatomical knowledge in life and death. ${ }^{23}$ 
Melanchthon is known to have been interested in the work of Vesalius; in a letter dated $29^{\text {th }}$ June I 552 he wrote that after seeing Vesalius' work he realized that corrections needed to be made to de Anima. A revised version titled Liber de Anima, was subsequently published incorporating many changes, making the visual reference to Vesalius all the more intriguing. It is plausible that the anonymous printer of the sheets was tasked with reflecting Melanchthon's interest in Vesalius' works. However the image retains its ambiguities and the portrait could just as easily be interpreted as contemptuous. In the guise of Vesalius the figure could even be seen to paradoxically mock the invitation to self-knowledge. Since anatomical knowledge of the body's interior is contingent upon its death, it is impossible, even for Vesalius, to know himself in anatomical terms.

The figure of Vesalius in the Wittenberg sheet holds something aloft in his right hand, much like Adam from Guldenmundt's fugitive sheet, printed in I 539. ${ }^{24}$ But it is not an apple that Vesalius holds; instead it is a fragmented part of his own anatomised body. The fragment is labelled ' $A$ ' and identified in the accompanying text as part of the eye. In fact this fragment seems to be better capable of vision than the eyes on Vesalius' face which are indistinctly coloured and have a cloudy quality. But what is the significance of this gesture? Does the remaking of Adam's body reach its completion in this sign of authority over anatomical knowledge?25 Or in the guise of Vesalius does the anatomised male body lay claim to new technological knowledge and through a firm grasp of the eye claim agency over vision?

The treatment of accessory figures such as the eye certainly deserves closer attention. While it is the eye that is given a privileged position in the male sheet, the foetus defines the female body (figure 6). Rather than being relegated to surface ornamentation superimposed over the top of the image, as it was in Vogtherr's design, the foetus sits upright, apparently unsupported, alongside the female figure. Moreover, it is repeated as an accessory figure at the bottom of the sheet, labelled ' $\mathrm{X}$ '. This repetition reminds Lutheran users of the relationship between part and whole and how each anatomised part contains and transmits the soul through its functions within the body. But the accessory figures of the foetus and the eye also play important roles in defensively securing gender difference in spite of the anatomical similarities between the two sexes. The active male body claims dominion over knowledge while the passive female body is defined by its reproductive organs. 
Yet the real anxiety is not just that male and female bodies come to resemble one another through dissection, the violated anatomical body offered up for visual consumption was frequently conceived of as feminine regardless of its actual gender. ${ }^{26}$ This danger was present all along but is amplified in fugitive sheets because the stomach is a productive space, filled with potential as much for the male figure as it is for the female figure. So it was the male body that came under particular threat from the cut and perhaps the use of Vesalius' likeness was not about anatomising the anatomist but reasserting an active role for the male body in spite of its apparent passivity as it is subjected to the user's prying investigations. Although the figure's identification with Vesalius tries to contain this voyeuristic potential by representing the body as actively engaged in the process of dissection, rather than merely compliant with it, the process of unveiling the bodily interior remains uncomfortably evocative of the erotic potentials of undressing - a state of transit that goes beyond the skin, dressing the insides of the body too. ${ }^{27}$

\section{Disrupting order: the user's remaking of the cut}

Maintaining order through the marks made on the surface of the sheet is a precarious balancing act between the production of visibility and invisibility. Sometimes this balance is unsettled and things that had previously been concealed or meanings that were held in check are suddenly revealed. This effect can be all too literal in some cases, as I realised when researching fugitive sheets based on Guldenmundt's Adam and Eve. Eve no longer contained her visceral insides; the intestines had slipped from their original position inside the body and were protruding from behind the flap of the torso, creating an unsettling visual image. A similar problem also affected Adam (figure 7). Where there had once been a leaf to protect his modesty there is now a tear in the sheet, revealing the internal anatomy. This observation may be about the condition of a particular pair of fugitive sheets but it has implications particularly relating to the ephemeral nature of the prints.

As de Certeau writes, reading is itself an ephemeral process, which: 'takes no measures against the erosion of time (one forgets oneself and also forgets), it does not keep what it acquires, or it does so poorly . . .2 ${ }^{28}$ In fugitive sheets it is not only the user who forgets, the prints themselves are incapable of holding on to the significations they produce. Knowledge revealed through the cut is only fleetingly brought into visibility before it is lost again, obscured 


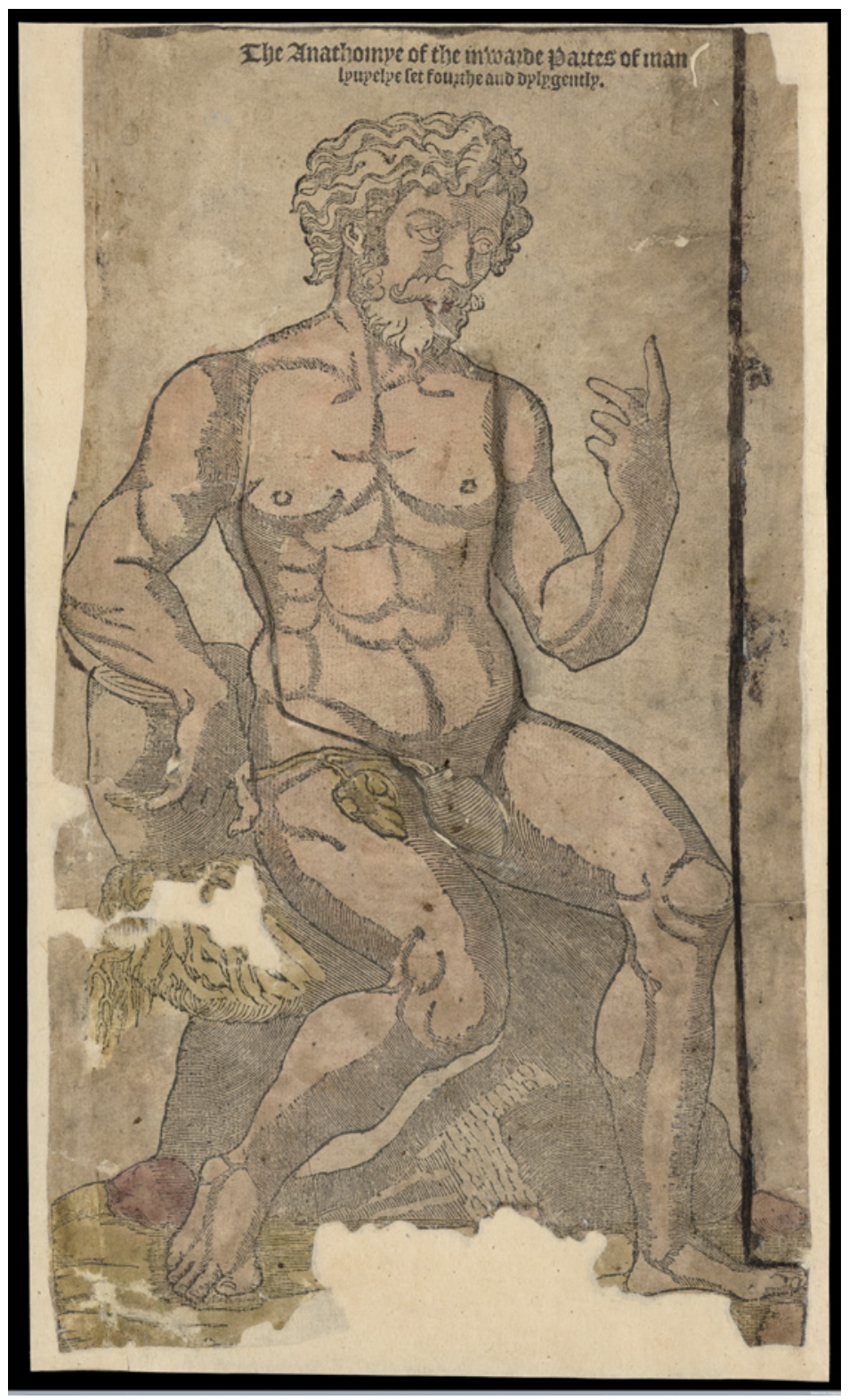

Figure 7 Male anatomical fugitive sheet based on Hans Guldenmundt's 'Adam' design: The Anathomye of the Inwarde Partes of Man, c. I545. Woodcut, $32 \times$ I9 $\mathrm{cm}$. The Wellcome Library, London, Photo: Wellcome Library. 
from view by another turn of the page. This is particularly noticeable when users reach the final layer of a fugitive sheet and find themselves looking at an empty space. The overturned flaps, folded back against their hinges, concealing the figure's head, are nothing more than an unintelligible mass of white shapes. Although the print's animated potential means that this process can be reversed, momentarily at least this view represents the point at which the experience can no longer be called erotic and knowledge therefore ceases to be produced. The sheets' flimsy materiality also heightens their ephemeral nature. Poorly executed assembly, deterioration due to repeated use over time, the delicacy of the paper; all affect the prints' success. Not only does damage to the prints disrupt the divide between inside and outside, it also reveals how precariously they hold meaning in check and the numerous potentials for failure in these types of assemblage, particularly when so much control is handed over to users.

Yet print has all too often been conceived as stable and verifiable. The exact repeatability of prints has been the subject of art historical investigations into its 'authority' and constructed as the means through which knowledge was inscribed. ${ }^{29}$ It has also been argued that repetition was mobilized as a powerful metaphor in the sixteenth century, turning abstract ideas and notions into permanent verifiable knowledge. ${ }^{30}$ Although more recently Michael Gaudio has shifted the discussion away from the old arguments about standardisation in reproduction and towards the materiality and processes of printing. ${ }^{3 \text { I }}$ Significantly though, a print's users could respond to and employ images or text in a multitude of different ways finding unpredictable, perhaps sometimes even undesirable uses for them.

It remains unclear whether printmakers would have assembled the moving parts in fugitive sheets or if it was left for the prints' users to paste the parts together themselves. ${ }^{32}$ If it was the latter then this would mean that the user began to shape the image and its meanings even before the sheet took on its finished appearance. Considerable variations in the assembly of fugitive sheets further contributes to the ambiguities about who was responsible for constructing the print, or exactly how the finished article was intended to look. There are numerous examples of fugitive sheets with imperfect assemblies that threaten to undermine the production of firm meaning through the cut; indexical letters are no longer clearly visible amongst the incoherent jumble of body parts and texts cease to be secured to the part of 
the image they define. When the order imposed by the cut breaks down like this, users find themselves having to negotiate with something unexpected, free to navigate their own way through the body and to feel out their own meanings between its layers.

Evidence in support of the user's role in piecing the prints together can be found amongst Vesalius' full page woodcuts for the 'Epitome', a shorter, somewhat simplified version of the Fabrica, also published in I 543. The text accompanying a print of the cardiovascular system provides advice for 'those who obtain unprepared copies, and put them together by their own efforts and industry, on the method of cutting each from the superfluous paper and pasting them on, and then of colouring them according to their ability and desire. ${ }^{33}$ This complicates the distinction between prints intended for scholarly and non-scholarly audiences and further demonstrates the efficacy of the fugitive technique for representing the body's spatialization. Evidently, for Vesalius the appeal of fugitive prints was not just about their commercial success, but in the way they marshalled print form itself, producing the possibility of movement and transformation through the physicality of the medium and not simply through the image. The cut does not simply separate matter and reveal form; it also enables material itself to take on new possibilities.

From the anatomist's first incision into the flesh to the printmaker's marks on the woodblock fugitive sheets depict a body that is in flux, where boundaries are visible yet invite and allow transgression. Crucially, the image - like the process of dissection it depicts - is defined by its temporality. While the cut aims to conjoin, the animated way in which it brings knowledge into visibility poses a problem for the construction of a stable, verifiable body of knowledge. Attempts to instil order and exert control over the process of revealing knowledge through the cut were variously aimed at manufacturing gender difference or displacing anxiety away from the practice of dissection. Some of the strategies employed resulted from the new technological possibilities of print; others had their roots in earlier manuscript traditions. But attempts to bring clarity to the image through a focus on its surface; for example the use of indexical marks and text; meant that sometimes these strategies found themselves in conflict with the spatialization of the body.

The tidy cut made by the printmaker promises a cleaner, more definite divide between the body's exterior/interior, and with it the potential for 
clear and definitive bodily knowledge. Yet this apparent clarity is still susceptible to disintegration. The cut is not always as tidy as it might first appear. Mistakes, aberrations and slips are all recorded on the wooden block and transferred onto the impressionable page. Moreover, the permanence of the mark and the exactness of the reproduction are challenged by the user's engagement in the cut. If the 'power of the anatomist is concentrated in the hand,' ${ }^{34}$ similarly, the process of viewing is inextricably linked with the tactility of fugitive sheets. The user's hand performs much the same probing exploration of this paper assemblage as the anatomist performs on the cadaver, and the ability of the user's tactile interaction to animate these prints cannot be underestimated.

\section{Notes}

I would like to thank Rose Marie San Juan and Mechthild Fend for their feedback, support and advice. Funding for this project was generously provided by the University College London Provost's Research Studentship in the Humanities.

I Andrea Carlino, 'Knowe Thyself: Anatomical Figures in Early Modern Europe' in RES: Anthropology and Aesthetics, vol. 27, Spring 1995, pp. 52-69, p. 54.

2 Le Roy Crummer, 'Early Anatomical Fugitive Sheets' in Annals of Medical History, vol. 5, no.3, Autumn I923, pp. I89-209; Andrea Carlino, 'Paper Bodies: A

Catalogue of Anatomical Fugitive Sheets, I 538-I687' in Medical History, no. I9, I999, pp. 336-348.

3 Roger Chartier, The Order of Books. Readers, Authors, and Libraries in Europe between the Fourteenth and Eighteenth Centuries, trans. Lydia G. Cochrane. Cambridge, I994.

4 Michel Foucault, Discipline and Punish. The Birth of the Prison, trans. Alan Sheridan, London, I977, pp. 3-3 I.

5 Andreas Vesalius, De humani corporis fabrica libri septem, Basel, I 543, p. I90.

6 Jonathan Sawday, The Body Emblazoned. Dissection and the Human Body in Renaissance Culture, London and New York, I995, p. 86.

7 Jacque Gelis, History of Childbirth: Fertility, Pregnancy and Birth in Early Modern Europe, trans. Rosemary Morris, Boston, I99I, pp. I27-I 30.

8 There are numerous examples of fugitive sheets where the text is printed on separate sheets, for example: Thomas Geminus, Interiorum Corporis Humani Partium Viva Delineation, London, c. I559; Johann Remmelin, Mirrors of the Microcosm, I6I 3.

9 Elizabeth Harvey, 'The Touching Organ: Allegory, Anatomy, and the Renaissance Skin Envelop' in Elizabeth Harvey (ed.), Sensible Flesh: On Touch in Early Modern Culture, Philadelphia, 2003, pp. 85-86.

Io Glenn Harcourt, 'Andreas Vesalius and the Anatomy of Antique Sculpture' in 
Representation. Special Issue: The Cultural Display of the Body, vol. I7, Winter, I987, pp. 28-6I, p. 49.

I I Ibid., p. 52.

I2 Translation of Auszlegung unnd beschreinbung der Anathomi as given in the following catalogue entry; Marisa Mandabach, 'Heinrich Vogtherr the elder' in Susan Dackerman (ed.), Prints and the Pursuit of Knowledge in Early Modern Europe, New Haven and Cambridge, 20I I, p. 68.

I3 Marisa Mandabach, 'Heinrich Vogtherr the elder', op. cit., pp. 68-70.

I4 Valerie Traub, 'Gendering mortality in early modern anatomies' in Feminist Readings of Early Modern Culture: Emerging Subjects, Valerie Traub, Lindsay Kaplan and Dympna Callaghan (eds.), Cambridge, I996, pp. 44-92, p. 50.

I5 Charles Donald O'Malley, Andreas Vesalius of Brussels, 1514-1564, Berkeley and Los Angeles, I964, pp. I77-I78.

I6 The inscription: 'Edita Vuitebergoe in gratiam studiosce iuuentutis, discentis elementa doctrinae Anatomice in libello de Anima. M. D. LXXIII' appears on the female sheet from the triptych.

I7 Sachiko Kusukawa gives a detailed account of the publication and impact of Melanchthon's de Anima at Wittenberg; Sachiko Kusukawa, The Transformation of Natural Philosophy: The Case of Philip Melancthon, Cambridge, I995.

I 8 Ibid.

I9 Rose Marie San Juan, Vertiginous Mirrors: The Animation of the Visual Image and Early Modern Travel, Manchester, 20 I I, pp. 2-3.

20 Translation of Vesalius as cited in J. B. de C. M. Saunders, and Charles D. O'Malley, The Illustrations from the Works of Andreas Vesalius of Brussels, New York, I950, pp. 317-320.

2 I Katherine Rowe, “'God's Handy Worke': Divine Complicity and the Anatomist's Touch" in The Body in Parts. Fantasies of Corporeality in Early Modern Europe, Carla Mazzio and David Hillman (eds.), London, I997, pp. 285-309, p. 293.

22 The resemblance was first noted by Crummer, who also pointed out that the hairline changed slightly between editions, perhaps as subsequent printers attempted to perfect the likeness: Crummer, 'Early Anatomical Fugitive Sheets' op. cit., pp. I99-200.

23 Rose Marie San Juan, 'The Turn of the Skull: Andreas Vesalius and the Early Modern Memento Mori' in Art History, Special Issue: The Erotics of Looking: Materiality, Solicitation and Netherlandish Visual Culture, vol. 35, no.5, 2012, pp. 958-975, p. 966.

24 No extant copies of Guldenmundt's 'Adam' are currently located. For a description of the prints, see Andrea Carlino, 'Paper Bodies: A Catalogue of Anatomical Fugitive Sheets, I 538-I687' in Medical History, supplement vol. I9, I999, pp. all, p. I38.

25 San Juan, 'The Turn of the Skull', op. cit., p. 97I.

26 Sawday, The Body Emblazoned, op. cit., pp. I I-I5; Traub, 'Gendering Mortality in Early Modern Anatomies', op. cit., pp. 54-55.

27 Mario Perniola, 'Between Clothing and Nudity' in Fragments for a History of the Human Body, Michel Feher, Ramona Naddaff and Nadia Tazi (eds.), New York, I989, pp. 237-65, pp. 258-259.

28 Michel de Certeau, The Practice of Everyday Life, trans. Steven Rendall, Berkeley, Los Angeles and London, I984, p. I74. 
29 William Ivins, Prints and Visual Communication, Cambridge MA and London, I953, p. 3.

30 Parshall, 'Imago Contrafacta', op. cit., pp. 554-579.

3 I Michael Gaudio, Engraving the Savage: The New World and Techniques of Civilisation, Minneapolis, 2008.

32 Amongst the recent literature regarding the production and assemblage of prints with moveable paper flaps, see Andrea Carlino, 'Paper Bodies', op cit.; Sachiko Kusukawa, Picturing the Book of Nature: Image, Text, and Argument in Sixteenth-Century Human Anatomy and Medical Botany, Chicago and London, 20I2; Suzanne Karr Schmidt, 'Memento Mori: The Deadly Art of Interaction' in Push Me, Pull You: Imaginative, Emotional, Physical, and Spatial Interaction in Late Medieval and Renaissance Art, Leiden, 20I I, pp. 26I-298.

33 Translation of Vesalius' Epitome as cited in J. B. de C. M. Saunders, and Charles D. O'Malley, The Illustrations from the Works of Andreas Vesalius of Brussels, op. cit., p. 220.

34 Elizabeth Harvey, 'The Touching Organ: Allegory, Anatomy, and the Renaissance Skin Envelop' in Elizabeth Harvey (ed.), op. cit., p. 90. 